\title{
Predicting Somatic Cell Count Standard Violations Based on Herd's Bulk Tank Somatic Cell Count. Part I: Analyzing Variation
}

\author{
J. M. Lukas, ${ }^{*}$ J. K. Reneau, ${ }^{\star 1}$ and M. L. Kinsel† \\ *Department of Animal Science, University of Minnesota, St. Paul 55108 \\ †Agricultural Information Management Inc., Ellensburg, WA 98926
}

\begin{abstract}
The present study examines the relationship between the bulk tank somatic cell count (SCC) mean and sigma (an estimate of variation) and the probability of exceeding a SCC standard. Daily or every other day, bulk tank SCC data were collected for 24 mo from 1,501 herds. Mean and sigma were estimated for each herd monthly and were compared between months and herd production categories using Kruskal-Wallis nonparametric ANOVA. The effect of month on bulk tank SCC mean and sigma was significant, with estimates for all summer months and most of the spring and fall months being significantly greater than estimates of mean and sigma in December 2004. Logistic regression models were developed to examine the relationship between month and herd production and the odds of a herd exceeding a SCC standard. The odds of exceeding a bulk tank SCC standard were significantly greater in the summer months and for smaller herds. A grid was constructed determining the probability of exceeding any of 5 SCC standards (200,000 to 600,000 cells $/ \mathrm{mL}$, step 100,000 cells $/ \mathrm{mL}$ ) in the following month, based on the mean and sigma of the past month. The violation probability grid can be used to assess the prospect of meeting quality premium goals and to proactively encourage more consistent performance in all the processes affecting bulk tank SCC.
\end{abstract}

Key words: bulk tank somatic cell count, variation, statistical process control

\section{INTRODUCTION}

Somatic cells are a routinely monitored milk characteristic. For the milk processor, bulk tank SCC (BTSCC) constitutes the basis for milk quality classification, pricing, and acceptability for global markets. Dairy Herd Improvement reports show that producing

Received August 28, 2007.

Accepted October 3, 2007.

${ }^{1}$ Corresponding author: renea001@umn.edu milk with BTSCC below 400,000 (SCC limit in European Union) remains a challenge for $25.2 \%$ of US dairy herds enrolled in DHI (Miller et al., 2007). Attempts to lower the SCC limit in the United States continue and have been recommended by the NMC (2001). Consumer pressure on the dairy industry may soon force producers to increase their efforts to consistently produce highquality milk (with low SCC; Norman et al., 2000).

For the producer and the consultant, BTSCC is an evaluation of all the processes on the farm that contribute to the quality of milk produced at the farm. The importance of milking procedure consistency has received prominent recognition in mastitis research (Ruegg, 2004). Improving consistency in employee performance is one of the reasons for moving toward standardized procedures on farms. Recent research showed that farms that impose their procedures with consistency are rewarded by better quality milk, healthier cows, and a faster, more efficient milking process (Ruegg, 2004).

From the perspective of milk production on the farm, or milk procurement by the processor, it is not enough to keep BTSCC average below a certain SCC level. It is important to assure that individual BTSCC meets the desired quality standard consistently, day after day, by controlling BTSCC variation. Unless a low mean BTSCC is accompanied with a lesser variation in BTSCC, there is little guarantee that each bulk tank shipped from the farm will test below a specified limit.

Quality improvement in nonagricultural industries has long recognized the importance of considering variation in process critique (Montgomery, 2005). Tools like statistical process control (SPC) focus on reducing process variation to improve product quality. Statistical process control charts are often used to plot current process mean and variation based on samples of process output. The current process mean is estimated from the sample average. Process variation, in SPC referred to as sigma, is most commonly estimated from the within-sample standard deviation, unless sample size equals 1 . Then, process variation is estimated from the average difference between 2 subsequent values, referred to in SPC as average moving range. Researchers 
have acknowledged the potential of using SPC in dairy management (Reneau and Kinsel, 2001; de Vries and Conlin, 2003). Monitoring variation in BTSCC can help assure consistently high performance of all processes contributing to milk quality on the farm. Some studies indicate that the variation of BTSCC might be affected by herd size (Belsito et al., 2004). Little is known, however, about the effect of day-to-day variation on the ability to produce milk below a given SCC standard. The purpose of this study was to 1) examine the effect of the size of herd production and month on BTSCC mean, day-to-day variation (sigma), and probability of exceeding a BTSCC quality standard and 2) construct a violation probability grid that determines the probabilities of exceeding 5 different BTSCC standards, depending on the mean and sigma of BTSCC.

\section{MATERIALS AND METHODS}

\section{Data}

Bulk tank SCC data were collected daily, or every other day, for 24 mo (January 2003 until December 2004) from 1,501 (6.4\% of the total population) Upper Midwest (North and South Dakota, Wisconsin, and Minnesota) dairy farms. To be included in the data set, herds had to have BTSCC data from at least 2 subsequent months in 2003 or 2004. Also, information on the average amount of milk shipped monthly had to be available for each farm in the data set. This data set was used to divide the herds into 5 herd production categories (HPC) based on the average amount of milk shipped each month in 2003 (USDA classification). Herd production category 1 included all herds with an average amount of milk shipped less than $22,680 \mathrm{~kg}, 2$ - from 22,680 to $45,360 \mathrm{~kg}, 3$ - from 45,360 to 90,720 $\mathrm{kg}, 4$ - from 90,720 to $226,800 \mathrm{~kg}$, and 5 - greater than $226,800 \mathrm{~kg}$. Assuming an average of $30 \mathrm{~kg} / \mathrm{cow}$ per day, HPC 1, 2, 3, 4, and 5 corresponded to fewer than 25 cows, from 25 to 49 cows, from 50 to 99 cows, from 100 to 249 cows, and 250 or more cows, respectively.

Therefore, it is assumed that the herds in the sample data set had a herd size distribution similar to the one reported in the United States in 2001 (NAHMS, 2003). Fifty percent of herds had less than 50 cows (vs. $49 \%$ in the United States), $28 \%$ had from 50 to 99 cows (vs. $30 \%$ in the United States), and $22 \%$ of herds had 100 or more cows (vs. $21 \%$ in the United States).

\section{Evaluating Herds in the Data Set}

Monthly means and sigmas were calculated from individual BTSCC values in 2003 or 2004, for each of the 1,501 herds. Because only a single sample is taken from each bulk tank, BTSCC sigma cannot be estimated from the within-sample standard deviation. Sigma was estimated by the moving range (AmR) of size 2 , averaged for each month, and divided by a constant (sigma = $A m R / d_{2}$ ). Constant $d_{2}$ is a tabulated value used to estimate standard deviation from a moving range. When standard deviation is estimated from a sample of size 2 , the value of the $d_{2}$ constant is 1.128 . Monthly mean was an arithmetic mean of individual BTSCC for each herd.

Each month, the maximum BTSCC in each herd was recorded and used to separately establish the SCC standard violation status of the herd for each of the 5 SCC standards. Each herd was declared positive for standard violation $(\mathrm{V}+)$ if the maximum BTSCC for that month was greater than the SCC standard or negative $(\mathrm{V}-)$ when the maximum BTSCC was equal or less than the SCC standard.

Logistic procedure of SAS was used to investigate the relationship between month and HPC and the odds of a herd being classified as $\mathrm{V}+$. Only main effects were examined. Change in odds was declared statistically significant when a $P$-value for the Wald statistics was $<0.05$.

Taking into consideration heteroscedasticity detected by Levene's test for equal variance $(P<0.05)$, KruskalWallis nonparametric 1-way ANOVA (SAS PROC NPAR1WAY) was used to test for the effects of month and HPC on BTSCC mean and sigma. Mean ranks were considered significantly different at $P<0.05$.

\section{Probability Grid for Herds Exceeding the BTSCC Standards}

Each month, a mean and a sigma category were assigned to each herd, based on the actual BTSCC mean and BTSCC sigma estimated for that month. Eleven categories were assigned for the mean $(100,000$ to 600,000 cells $/ \mathrm{mL}$, step 50,000 cells $/ \mathrm{mL}$ ). Likewise, 10 categories were assigned for the sigma $(10,000$ to 30,000 cells/mL, step 10,000 cells $/ \mathrm{mL} ; 30,000$ to 75,000 cells/ $\mathrm{mL}$, step 15,000 cells/mL; and 75,000 to 175,000 cells/ $\mathrm{mL}$, step 25,000 cells $/ \mathrm{mL}$ ). For each of the $23 \mathrm{mo}$ (February 2003 until December 2004), the maximum BTSCC was recorded for each of the 1,501 herds. This information was matched with the mean and sigma category identified for the herd in the previous month (January 2003 until November 2004). For each month, the fraction of herds that exceeded the SCC standard in the following month was identified within each mean and sigma combination and for each of the 5 SCC standards $(200,000$ cells $/ \mathrm{mL}, 300,000$ cell $/ \mathrm{mL}, 400,000$ cells $/ \mathrm{mL}$, 500,000 cells $/ \mathrm{mL}$, and 600,000 cells $/ \mathrm{mL}$ ).

The results were presented in a grid showing the probability of exceeding a SCC standard in the current 


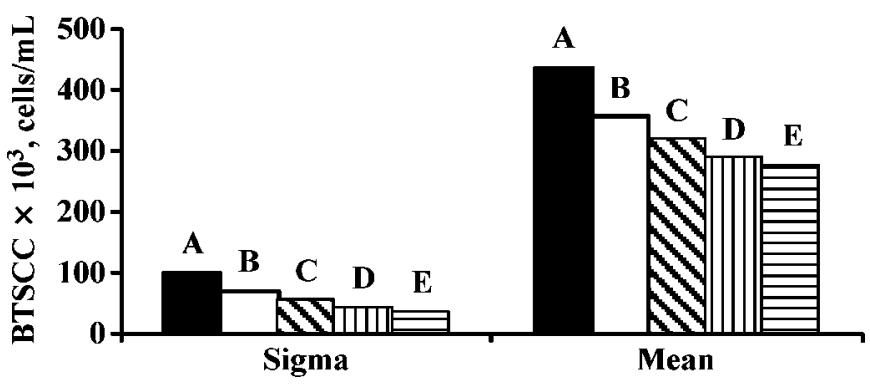

Figure 1. Mean and sigma of the bulk tank SCC (BTSCC) by herd production category (HPC). From left, bars represent HPC 1 (black bar), HPC 2 (white bar), HPC 3 (diagonally striped bar), HPC 4 (vertically striped bar), and HPC 5 (horizontally striped bar). ${ }^{\mathrm{A}-\mathrm{E}} \mathrm{Bars}$ with different letters represent means that are different $(P<0.05)$.

month depending on the mean and sigma of BTSCC of the previous month. To eliminate potential outliers characterized by an unusually small or large variation for the calculated mean in BTSCC, each combination of mean and sigma had to be represented by at least 50 herds to be included in the grid.

\section{RESULTS AND DISCUSSION}

\section{Evaluation of the Herds in the Data Set}

Mean and sigma by HPC, and for each of the 24 mo, within the sample of 1,501 herds are presented in Figures 1 and 2, respectively. Both the means and sigmas differed significantly among all 5 HPC (Figure 1). The lowest mean and sigma $(P<0.05)$ were observed in December 2004 (Figure 2). The effect of month on BTSCC mean and sigma was significant. Estimates for all summer months (June, July, and August) and most of the spring (March, April, May 2003, and March 2004) and fall (September 2003 and 2004 and October 2003) months were significantly greater from estimates of mean and sigma in December 2004 (Figure 2). Greater odds of exceeding a SCC standard are also associated with summer months (Figure 3 ) and smaller herds (Figure 4).

The relationship among herd production, month, and BTSCC sigma should be taken into account when comparing variation within and between herds. The same variation that is considered high in the winter months or in a larger herd might be average among smaller herds or in the summer months.

The general observation that larger herds have lower BTSCC means has been made by others (Ott and Novak, 2001). The decrease in variation with the increase of number of cows in the herd can be partly explained by the greater effect of the milk from a cow with high SCC on the BTSCC in a small herd vs. a larger herd (Belsito et al., 2004). In a larger herd, BTSCC will change by a smaller increment as a result of the SCC level of an individual cow as compared with a smaller herd. Subsequently, in a larger herd, the effect of milk from a high-SCC quarter on BTSCC variation will be of smaller magnitude. This makes maintaining BTSCC below a chosen SCC level more challenging in smaller herds. This also requires the dairy producers of those herds to be more vigilant in monitoring the SCC of individual cows, as well as the mean and sigma in their BTSCC. It is also true, however, that trying to quickly reduce BTSCC mean or sigma to assure keeping a specific SCC level in larger herds may require more time and effort. More cows will have to be identified as highSCC contributors, and their milk will have to be diverted from the bulk tank.

Currently, a Web-based SPC milk component monitoring system (MilkLab, http://www.dairyperformance.com) automatically plots BTSCC and milk component control charts online. This creates an opportunity for the milk producers to obtain information on the quality of milk leaving their farm at every pickup. This kind of monitoring will give the farmer the opportunity to take action and investigate the root cause of any observed changes in BTSCC sooner, before they lead to SCC standard violations.

Bulk tank SCC standard violation prevalence decreases as the BTSCC standard becomes greater (Figure 3) and herd production larger (Figure 4). Number of 200,000 cells $/ \mathrm{mL}$ BTSCC violations seems to vary little by season (Figure 3). The percentage of herds violating this standard is also very large (average 95\%). This indicates that regardless of season or HPC, the 200,000 cells/mL standard was very hard to meet for any of the 1,501 herds monitored for the $24 \mathrm{mo}$. The herds that were able to keep the 200,000 cells $/ \mathrm{mL}$ SCC standard represented all $5 \mathrm{HPC}$. Also, odds of exceeding the 200,000 cells $/ \mathrm{mL}$ SCC for HPC 3 and 4 were not different from HPC 5, with odds ratios 1.07 and 0.88 and $P=0.43$ and 0.17 , respectively. The differences between the number of herds violating the standard depending on the HPC were also smaller than for the remaining 4 standards. There was a $4 \%$ difference in prevalence between the HPC with the highest and lowest prevalence for the 200,000 cells $/ \mathrm{mL}$ standard and $26 \%$ or more difference for the remaining SCC standards. This implies that those dairies that succeeded in meeting the 200,000 cells/mL standard had sufficiently intense management, leading to consistency in process performance, regardless of season or HPC.

\section{Violation Probability Grid}

The violation probability grid (Table 1) shows how the probability of violation in the following month in- 


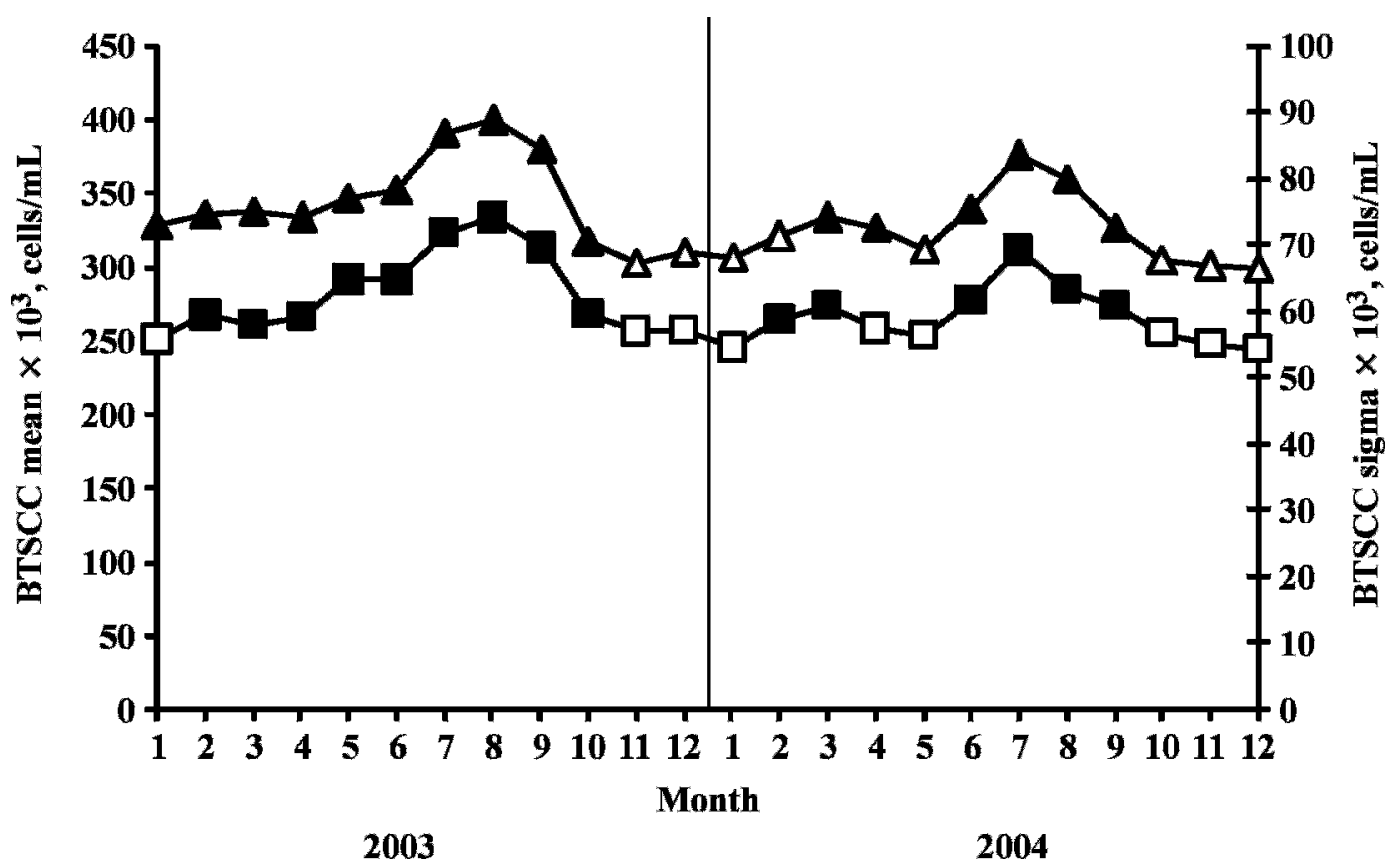

Figure 2. Bulk tank SCC (BTSCC) sigma $(\square)$ and mean $(\triangle)$ by month. Months labeled with filled symbols $(\boldsymbol{\square}, \mathbf{\Delta})$ are different $(P<0.05)$ from December 2004. Vertical line marks the end of year 2003 and beginning of year 2004.

creases as the mean and sigma of BTSCC in the current month increases. However, for the 400,000 cells $/ \mathrm{mL}$ standard, the relationship between mean and sigma and probability of violations does not hold across the greater BTSCC sigma and mean categories. The same relationship was repeated across the remaining 4 standards (data not shown). Previous research has identified a strong relationship between BTSCC mean and sigma with a coefficient of determination of 0.50 (Reneau and Lukas, 2006). Herds with greater means tend to have greater sigma (Reneau and Lukas, 2006), resulting in a less-predictable performance. This weakens the relationship among mean, sigma, and probability of violation at greater BTSCC mean and sigma categories.

The grid demonstrates how herds achieving an average BTSCC of 250,000 cells $/ \mathrm{mL}$ or less can still have an $84 \%$ chance of exceeding 400,000 cell $\mathrm{s} / \mathrm{mL}$ if their variation is high. This exemplifies how a low mean BTSCC unless accompanied by a low variation can give a false impression as to the capability of a herd of meeting a specific SCC standard.

Based on this analysis, a worksheet was developed by the authors that calculates the mean and sigma for a given set of BTSCC data. The worksheet also displays the probability of exceeding a given SCC standard based on the calculated mean and sigma. The worksheet has been developed as an Excel file named "BTSCC Monitoring Spreadsheet". It is available online at: http://www.ansci.umn.edu/dairy/quality\%20counts/ SPREADSHEETS/MonitoringBTSCC.xls.

Violation probability estimations are based on a study of 1,501 herds monitored for 24 mo. This makes it a reliable tool for dairy managers and consultants. Monitoring BTSCC sigma and using the violation probability grid will not indicate to the producer which one of the processes on the dairy farm is causing the change in BTSCC. It can, however, warn the producer of an increasing probability of a standard violation before such a violation occurs. The actual response to this warning system will depend on the risk management of the producer. This makes the probability grid a very flexible tool, a tool that lets the producer decide what level of risk he or she is willing to take before initiating any preventive action.

\section{CONCLUSIONS}

Both herd production and season affect the BTSCC sigma and have to be considered when BTSCC variation comparisons between and within herds are made. The probability of violation increases with BTSCC mean and sigma. Monitoring BTSCC mean and sigma has the potential of warning the producer of an upcoming violation before such a violation occurs. The violation probability grid developed in this study can be used by the producer or milk processors to assess the prospect 


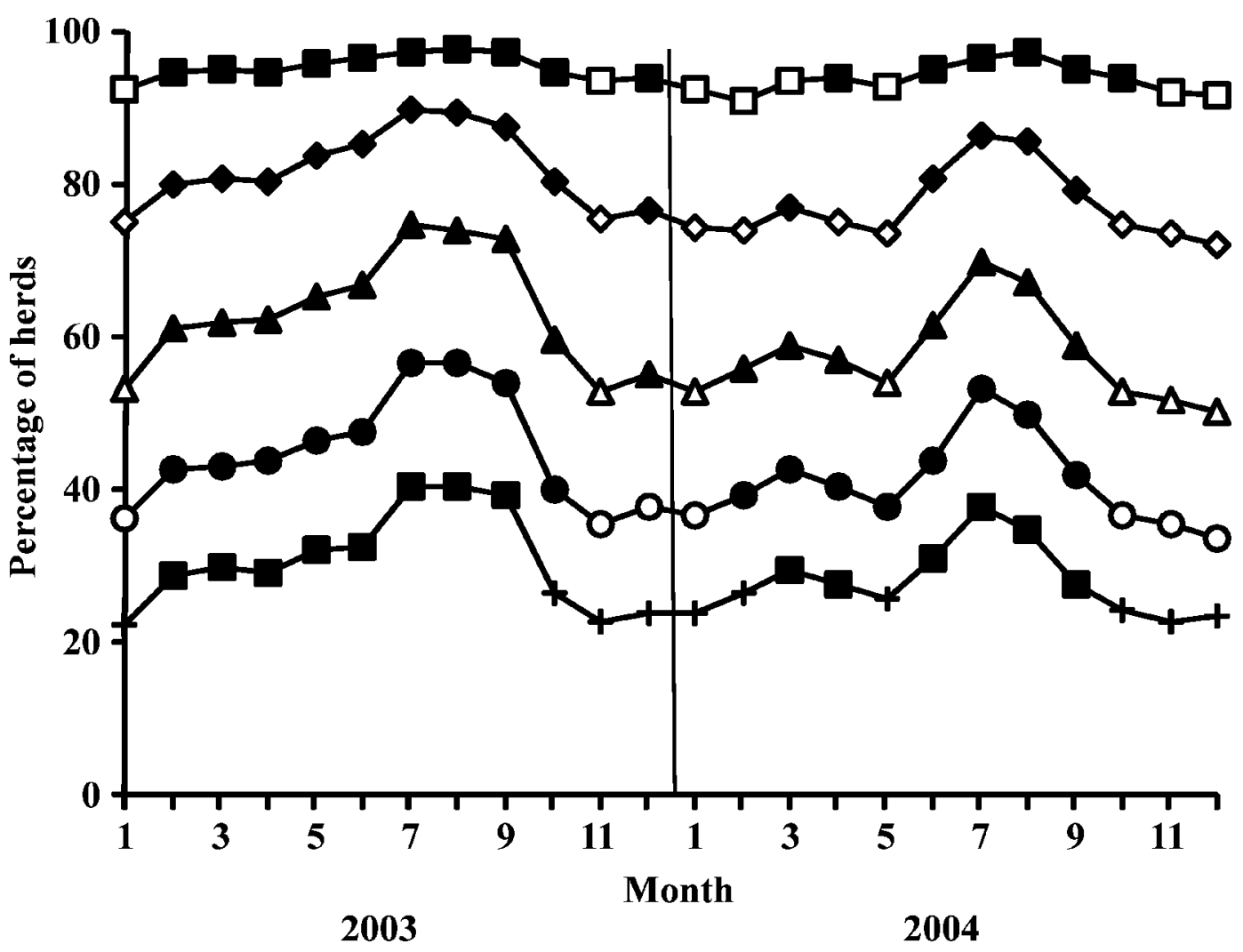

Figure 3. Prevalence of the 200,000 cells $/ \mathrm{mL}(\square), 300,000$ cells $/ \mathrm{mL}(\diamond), 400,000$ cells $/ \mathrm{mL}(\triangle) 500,000$ cells $/ \mathrm{mL}(\bigcirc)$, and 600,000 cells $/$ $\mathrm{mL}(+)$ bulk tank SCC (BTSCC) standard violations by month. Vertical line marks the end of year 2003 and beginning of year 2004 . Within each series, points labeled with filled symbols $(\square, \forall, \mathbf{\Delta ,}, \mathbf{Q})$ represent months in which odds of exceeding the standard are different $(P$ $<0.05)$ as compared with December 2004.

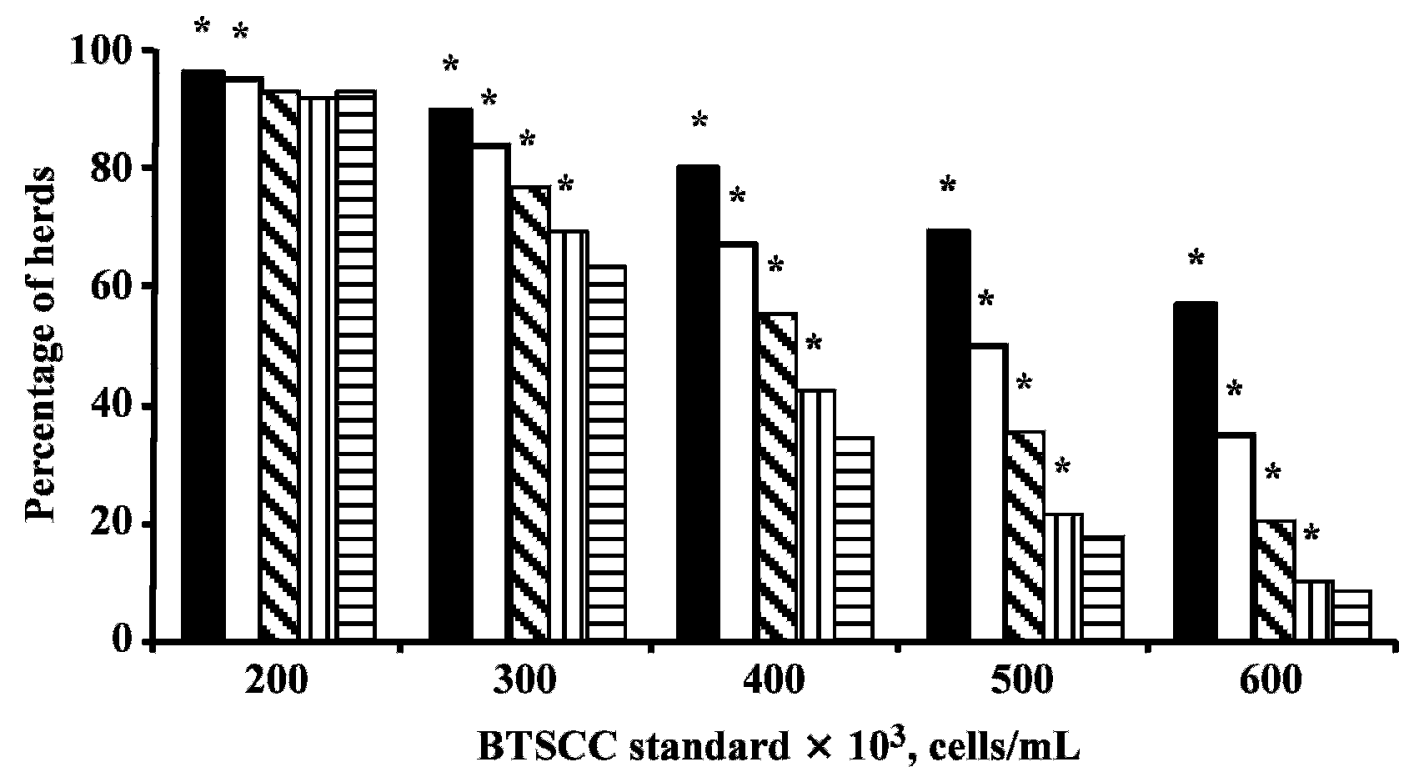

Figure 4. Prevalence of the bulk tank SCC (BTSCC) standard violations by herd production category (HPC). From left, bars represent HPC 1 (black bar), HPC 2 (white bar), HPC 3 (diagonally striped bar), HPC 4 (vertically striped bar), and HPC 5 (horizontally striped bar). Bars marked with an asterisk represent HPC for which odds of exceeding the standard are different as compared with HPC $5(P<0.05)$. 
LUKAS ET AL.

Table 1. Probability of exceeding a 400,000 cells $/ \mathrm{mL}$ of SCC standard in the following month depending on the bulk tank SCC mean and sigma estimated for the current month ${ }^{1}$

\begin{tabular}{|c|c|c|c|c|c|c|}
\hline \multirow[b]{2}{*}{ Sigma $^{3}$} & \multicolumn{6}{|c|}{ Mean $^{2}$} \\
\hline & 100 to 149 & 150 to 199 & 200 to 249 & 250 to 299 & 300 to 349 & 350 to 400 \\
\hline \multicolumn{7}{|l|}{10 to 20} \\
\hline$\%$ & 4 & 6 & 7 & & & \\
\hline $\mathrm{n}$ & 19 & 23 & 12 & & & \\
\hline \multicolumn{7}{|l|}{20 to 30} \\
\hline$\%$ & 5 & 9 & 14 & 31 & 51 & 81 \\
\hline $\mathrm{n}$ & 39 & 110 & 117 & 139 & 98 & 52 \\
\hline \multicolumn{7}{|l|}{30 to 45} \\
\hline$\%$ & 7 & 13 & 23 & 45 & 68 & 92 \\
\hline $\mathrm{n}$ & 36 & 178 & 393 & 674 & 657 & 473 \\
\hline \multicolumn{7}{|l|}{45 to 60} \\
\hline$\%$ & 17 & 21 & 33 & 55 & 73 & 89 \\
\hline $\mathrm{n}$ & 14 & 101 & 352 & 683 & 870 & 773 \\
\hline \multicolumn{7}{|l|}{60 to 75} \\
\hline$\%$ & & 23 & 40 & 56 & 75 & 91 \\
\hline $\mathrm{n}$ & & 36 & 161 & 413 & 605 & 699 \\
\hline \multicolumn{7}{|l|}{75 to 100} \\
\hline$\%$ & & 33 & 44 & 57 & 80 & 89 \\
\hline $\mathrm{n}$ & & 17 & 84 & 209 & 488 & 678 \\
\hline \multicolumn{7}{|l|}{100 to 125} \\
\hline$\%$ & & & & 62 & 77 & 89 \\
\hline $\mathrm{n}$ & & & & 58 & 140 & 245 \\
\hline \multicolumn{7}{|l|}{125 to 150} \\
\hline$\%$ & & & & & 81 & 88 \\
\hline $\mathrm{n}$ & & & & & 52 & 84 \\
\hline
\end{tabular}

${ }^{1}$ Both the percentage $(\%)$ and number $(\mathrm{n})$ of herds exceeding the standard within each mean and sigma combination are presented.

${ }^{2}$ Bulk tank SCC mean category in 1,000 cells $/ \mathrm{mL}$.

${ }^{3}$ Bulk tank SCC sigma category in 1,000 cells $/ \mathrm{mL}$.

of meeting quality premium goals. It is also a tool designed for dairy consultants to encourage improvement in process consistency as means of further BTSCC control.

\section{ACKNOWLEDGMENTS}

We would like to acknowledge Land O'Lakes Inc. (Arden Hills, MN) for their valuable help and cooperation with this project.

\section{REFERENCES}

Belsito, J. E., A. de Vries, and R. P. Natzke. 2004. Evaluation of the DHI Hot List as a tool to reduce bulk tank somatic cell counts. J. Dairy Sci. 87(Suppl. 1):141. (Abstr.)

de Vries, A., and B. J. Conlin. 2003. Economic value of timely determination of unexpected decreases in detection of estrus using control charts. J. Dairy Sci. 86:3516-3526.

Miller, R. H., H. D. Norman, and A. H. Sanders. 2007. Somatic cell counts of milk from Dairy Herd Improvement herds during 2006 (USDA AIPL Research Report SCC7 3-06). http://www.aipl.arsusda.gov/publish/dhi/current/sccrpt.htm Accessed Aug. 13, 2007.
Montgomery, D. C. 2005. Introduction to Statistical Quality Control. 5 th ed. J. Welter, J. Powers, S. Dumas, D. Stanley, and T. Kulesa, ed. John Wiley \& Sons Inc., Hoboken, NJ.

NAHMA. 2003. Dairy 2002 Part II: Changes in the United States Dairy Industry, 1991-2002. http://www.aphis.usda.gov/vs/ceah/ ncahs/nahms/dairy Accessed Aug. 13, 2007.

NMC. 2001. NMC continues to support lower SCC regulatory limit. http://www.nmconline.org/articles/SCC2001.htm Accessed Aug. $13,2007$.

Norman, H. D., R. H. Miller, J. R. Wright, and G. R. Wiggans. 2000. Herd and state means for somatic cell count from Dairy Herd Improvement. J. Dairy Sci. 83:2782-2788.

Ott, S. L., and P. R. Novak. 2001. Association of herd productivity and bulk-tank somatic cell counts in U.S. dairy herds in 1996. J. Am. Vet. Med. 218:1325-1330.

Reneau, J. K., and M. L. Kinsel. 2001. Record systems and herd monitoring in production-oriented health and management programs in food producing animals. Pages 107-146 in Herd Health. O. M. Radostits, ed. W. B. Saunders Co., Philadelphia, PA.

Reneau, J. K., and J. M. Lukas. 2006. Using statistical process control methods to improve herd performance. Vet. Clin. North Am. Food Anim. Pract. 22:171-193.

Ruegg, P. 2004. Pre-milking cow preparation - secrets of producing high quality milk. Pages $34-41$ in Natl. Mastitis Counc. Reg. Meet. Proc., Bloomington, MN. Natl. Mastitis Counc. Inc., Madison, WI. 